\title{
Healthcare resource use and medical costs for the management of oesophageal cancer
}

L. G. Gordon ${ }^{1,2}$, S. Eckermann ${ }^{4}$, N. G. Hirst ${ }^{2}$, D. I. Watson ${ }^{3}$, G. C. Mayne ${ }^{3}$, P. Fahey ${ }^{5}$ and D. C. Whiteman ${ }^{1}$ for the Australian Cancer Study Clinical Follow-Up Study

${ }^{1}$ Queensland Institute of Medical Research, Population Health Department, Royal Brisbane Hospital, and ${ }^{2}$ Centre for Applied Health Economics, Griffith University, Brisbane, Queensland, ${ }^{3}$ Flinders University Department of Surgery, Flinders Medical Centre, Adelaide, South Australia, and ${ }^{4}$ Centre for Health Service Development, University of Wollongong, Wollongong, and ${ }^{5}$ National Centre in HIV Epidemiology and Clinical Research, University of New South Wales, Darlinghurst, New South Wales, Australia

Correspondence to: Dr L. G. Gordon, Centre for Applied Health Economics, Griffith University, University Drive, Meadowbrook, Brisbane, Queensland 4131, Australia (e-mail:

Louisa.Gordon@griffith.edu.au)

Background: This study examined the interaction between natural history, current practice patterns in diagnosis, monitoring and treatment of oesophageal cancer, and associated health resource utilization and costs.

Methods: A cost analysis of a prospective population-based cohort of 1100 patients with a primary diagnosis of oesophageal cancer was performed using chart review from the Australian Cancer Study Clinical Follow-Up Study. The analysis enabled estimation of healthcare resources and associated costs in 2009 euros by stage of disease and treatment pathway.

Results: Most patients (88.5 per cent) presented with stage II, III or IV cancer; 61.1 per cent (672 of 1100) were treated surgically. Overall mean costs were €37 195 (median €29 114) for patients undergoing surgery and $€ 17281$ (median $€ 13$ 066) for those treated without surgery. Surgery contributed 66.4 per cent of the total costs (mean €24 697 per patient) in the surgical group. In the non-surgical group, use of chemotherapy was more prevalent (81.9 per cent of patients) and contributed 61.1 per cent of the total costs. Other important cost determinants were gastro-oesophageal junction tumours, treatment location and tumour stage. Mean costs of those monitored for Barrett's oesophagus (7.3 per cent of patients) were lower, although about onethird still presented with advanced-stage cancer. 
Conclusion: Overall costs for managing oesophageal cancer were high and dominated by surgery costs in patients treated surgically and by chemotherapy costs in patients treated without surgery; radiotherapy, treatment location and cancer subtype were also important. Monitoring for Barrett's oesophagus and earlier stage detection were associated with lower management costs, but the potential net benefit from surveillance strategies needs further investigation.

\section{+A: Introduction}

The incidence of oesophageal adenocarcinoma in Western nations has grown four- to fivefold over the past 30 years $^{1,2}$, with a parallel increase in the number of deaths from this cancer of 4-7 per cent annually ${ }^{1}$. Less than 20 per cent of people currently diagnosed with oesophageal cancer can expect to survive beyond 5 years ${ }^{1}$, although there is much scope for improving survival given that early detection of oesophageal adenocarcinoma is associated with a 5-year survival rate of 70-95 per cent ${ }^{3}$.

The mainstay of treatment for earlier stage cancer is oesophagectomy. Chemotherapy and radiotherapy are used before surgery in patients undergoing resection of more advanced disease, and are the principal treatment in patients unwilling or unfit for surgery, as well as in those with disseminated disease. The clinical course of the cancer can vary markedly, with a low proportion of at-risk patients currently proceeding straight to diagnosis and surgery ${ }^{4}$. A detailed understanding of resource utilization for the treatment of this disease remains elusive. Compared with many other cancer populations, healthcare resource use and costs in patients diagnosed with oesophageal cancer may potentially be high owing to a protracted disease process, frequent treatment-related complications, and the high number and frequency of monitoring and diagnostic investigations ${ }^{4-6}$.

Considering the relatively poor survival outlook for patients with advanced disease, there is a strong incentive to develop health technologies that will either detect cancer earlier or treat patients more effectively, while containing healthcare costs. Management options have expanded over the past decade, with new ablative therapies, enhanced imaging, endoscopic mucosal resection, and calls for standardized surveillance of Barrett's oesophagus ${ }^{7-9}$. However, these strategies are suitable only for early-stage disease, and most patients still present with advanced cancer. 
Only one previous study has attempted to track healthcare resources and costs in treating oesophageal cancer at the patient level. That study was conducted a decade ago, before many of the current management and therapy alternatives were available, and it analysed a sample of only 29 patients from one centre ${ }^{4}$. It was not large enough to allow practice patterns to be explored. Hence, studies assessing the cost-effectiveness of alternative oesophageal cancer treatments ${ }^{10,11}$ in jurisdictions of interest have relied on assumptions, rather than patient data, to inform treatment pathways and associated base-level probabilities, outcomes and their interaction with treatment effects $^{12,13}$. The absence of evidence to inform practice patterns, and the interaction of practice patterns with natural history, reduce the validity of the findings of all of these modelling studies $^{10,11,14}$. In view of these gaps in the evidence, the present authors sought to identify treatment patterns and their interaction with natural history, to quantify the type and extent of resources used to treat actual patients with oesophageal cancer in Australia, and to analyse the attendant healthcare costs.

\section{+A: Methods}

Patient-level clinical practice, healthcare and medical outcome data were collected during the Australian Cancer Study Clinical Follow-Up (ACS CFU) Study for a cohort of 1100 patients with oesophageal cancer. These patients were previously enrolled in the ACS, a nationwide case-control study. The study was approved by the Human Research Ethics Committees of the Queensland Institute of Medical Research and participating hospitals. Eligible persons were aged 18-79 years, had a primary diagnosis of invasive adenocarcinoma, squamous cell carcinoma of the oesophagus or adenocarcinoma of the gastro-oesophageal junction, were English-speaking and provided consent for the investigators to undergo medical chart review. Full details have been published previously ${ }^{15}$. Briefly, study participants were recruited through their treating doctors or state-based cancer registries in the mainland Australian states between 1 July 2002 and 30 June 2005 (registration of cancer is mandatory in all states and territories of Australia). A total of 1577 patients received an invitation to participate in the study, of whom 1102 patients (858 via clinics and 244 through cancer registries) consented (69.9 per cent of all invited; 35.0 per cent of all living and deceased persons in mainland Australia who had been diagnosed with incident oesophageal cancer). Two patients were removed from analysis because of unclear diagnosis. Participants were asked to complete a survey providing information on 
sociodemographics, disease symptoms and health behaviours. A total of 44 consenting participants did not return these surveys but remained eligible for clinical follow-up.

$+B$ : Cost perspective, data collection of resources used, and duration of follow-up

Following recommended guidelines ${ }^{16}$, costs associated with oesophageal cancer treatment were estimated from a health provider (government) perspective. Data were abstracted from medical charts on to standard case-report forms by trained research nurses. Information was collected on each patient's investigations by point of incidence at diagnosis, before and after treatment (endoscopy, computed tomography (CT)/positron emission tomography (PET), X-rays, etc.), operative treatment and related adverse events, endoscopic therapies (argon beam, laser, photodynamic therapy, stenting), chemotherapy and radiotherapy. Resource data were collected from date of diagnosis (including peridiagnostic tests) to date of death or last date of follow-up. The mean duration of follow-up for the sample was 4.3 years. The Australian National Death Index was searched periodically during the study to monitor mortality for the cohort. Survival was calculated in days from the date of diagnosis to the date of death, or administratively censored at 31 January 2008.

$+B$ : Estimating costs from resource use

Costs for the primary surgical treatment were derived from the clinical costing department of a large metropolitan hospital (Royal Brisbane and Women's Hospital) where a separate and recent sample of 40 participants had been treated surgically for oesophageal cancer. Cost per hospital inpatient separation by number of hospital days admitted was modelled for the three most common Australian Refined Diagnosis-Related Groups ${ }^{17}$ : G03A, 'Stomach, oesophageal and duodenal procedures for malignancy'; G42A, 'Other gastroscopy for a major digestive disease’; and G60A, 'Digestive malignancy with complications'. Costs for chemotherapeutic agents were estimated from the 2008 Chemotherapy Pharmaceuticals Access Program ${ }^{18}$. Unit prices for imaging tests, radiotherapy, clinic consultations and all other outpatient investigations were obtained from the hospital clinical costing department, where available, or from the Australian Medicare Benefits Schedule ${ }^{19}$. Costs associated with the resource implications of any complications while on chemotherapy or any supportive care medications were not collected and were omitted from the analyses. Resources relating to palliative care provided by community health services were omitted but all in-hospital palliative treatments such as endoscopic dilatation or stenting, and palliative chemotherapy were included. 


\section{$+B$ : Analysis}

All analyses were stratified into patients who underwent surgical resection (surgical group) versus patients who did not undergo surgical resection (non-surgical group). The non-surgical group included patients who were unfit for surgery, had metastatic disease at presentation, or had declined surgical resection. Stratification was undertaken because of the different disease presentation and treatment implications across the two groups.

Cancer staging data were not reported routinely for all participants at diagnosis and were missing for 48.7 per cent of patients. To address this, stage data were imputed by fitting an ordered logit regression model with stage as the dependent variable and generating predicted values for each stage category for each patient. To allow for uncertainty in modelling, a random variable was generated from the uniform distribution on 0-1 interval and these values were compared with the predictions in order to assign a stage category for the missing cases. The random variable was necessary so that the variance in the subsequent regression models was not overestimated $^{20}$.

Costs were updated to 2009 Australian dollars (AUD) using the Consumer Price Index ${ }^{21}$ and converted to euros where $1 \mathrm{AUD}=€ 0.519^{22}$. Descriptive statistics were generated for medical costs by the major resource categories. Bootstrapping was employed to estimate distributions around mean costs per participant and associated 95 per cent confidence intervals (c.i.), allowing for right-skewing of cost data ${ }^{23}$. One thousand bootstrapped samples from the original skewed distribution, with replacement, were run using the bias-corrected and accelerated approach $^{24}$. The Wald test was used to assess subgroup differences ${ }^{24,25}$. Tests were two-sided and results were considered statistically significant when $P<0.050$.

To account for the right-censored data, mean costs by surgical versus non-surgical groups were assessed for variation in baseline clinical or patient factors using the three-part model of Basu and Manning ${ }^{26}$. First, an accelerated failure-time generalized gamma regression model provided the survival and hazard functions. Second, for patients whose costs were fully observed, a gamma generalized linear model with square-root link was undertaken. Third, for patients in whom censoring occurred, an extended estimating equation using a flexible Box-Cox link function and power variance function was performed (using STATA command 'PGLM') ${ }^{27}$. Goodness-of-fit and model specification were assessed with normality tests, Pearson’s correlation, Pregibon's link test, and visual assessment for systematic bias in the residuals across 
deciles of linear predictors and for v-fold cross-validation with the Copas test for overfitting ${ }^{28}$. Data were analysed using STATA ${ }^{\circledR}$ SE 11.0 (StataCorp, College Station, Texas, USA).

\section{+A: Results}

The mean age of participants was 64 years at diagnosis; 79.6 per cent were men, and most were partnered (77.4 per cent) (Table S1, supporting information). Adenocarcinoma of the oesophagus was present in 33.4 per cent of participants, 38.6 per cent had adenocarcinoma of the gastrooesophageal junction and 27.7 per cent had squamous cell carcinoma of the oesophagus. Of patients with a known cancer stage, 11.5 per cent had stage I cancer, 34.8 per cent stage II, 28.7 per cent stage III and 25.0 per cent stage IV. A total of 79 (7.3 per cent) of 1081 participants were being monitored for Barrett's oesophagus: stage I cancer, 16.3 per cent (23 of 141); stage II, 8.0 per cent (33 of 413); stage III, 5.5 per cent (19 of 348); stage IV, 2.2 per cent (4 of 179). Of the patients under surveillance for Barrett's oesophagus, 29 per cent (23 of 79) presented with stage III or IV oesophageal cancer, and 17 of these 23 patients were treated surgically. Overall median survival was 23.5 (interquartile range (i.q.r.) 1.5-78.1) months and was longer for patients treated surgically (median 33.0, 1.8-78.1) than for those not treated surgically (13.2, 2.1-72.6). Patients receiving routine surveillance for Barrett's oesophagus had a median survival of 47 (range 5-84) months, compared with 22 (2-84) months for all other patients.

\section{$+B:$ Resources used}

A total of 3679 staging investigations were performed before treatment in 1098 participants (mean 3.3 per participant) with CT representing 28.0 per cent and PET 13.6 per cent of all tests (Tables 1 and 2). Radiotherapy was given to 43.9 per cent (295 of 672) of surgical patients and 81.5 per cent (347 of 426) of non-surgical patients. Of patients with stage IV cancer who were treated surgically, a higher proportion received chemotherapy and radiotherapy (70 and 75 per cent respectively) compared with those with stage I-III cancers (32.3 and 59.6 per cent respectively) (Table 1). Of patients with stage IV cancer who were not treated surgically, 66.2 per cent underwent diagnostic PET versus 35.3-43.6 per cent of those with stage I-III cancers (Table 2). Of participants with squamous cell carcinoma, 66.9 per cent received both radiation and chemotherapy, compared with 52 per cent of patients with adenocarcinoma of the oesophagus and 37.6 per cent of those with adenocarcinoma of the gastro-oesophageal junction. The four most commonly used chemotherapy agents were 5-fluorouracil, cisplatin, epirubicin 
hydrochloride and carboplatin. These accounted for 93.6 per cent of all administrations; a total of 25 agents was used in the sample overall.

A total of 672 participants (61.2 per cent) underwent surgery; of these, 124 (18.5 per cent) had preoperative chemotherapy and radiotherapy. Hospitalization for the surgical treatment of oesophageal cancer resulted in approximately 12600 (mean 18.8; median 15) inpatient days. Hospital days were right-skewed with the fifth and 95th percentiles being 9 and 43 days respectively. A further 2244 postoperative investigations were performed to assess surgical outcomes. Postoperative adverse events were most frequently attributed to pneumonia (18.2 per cent), arrhythmia (10.8 per cent), anastomotic leak (10.1 per cent) and wound infection (8.3 per cent) (Table 3). The length of hospital stay was generally longer for those with than those without operative complications (mean 23.0 versus 13.7 days; $P<0.001$ ). However, some 25.0 per cent of individuals who experienced complications had a shorter than average stay (14 days or less) and, conversely, 25.0 per cent of patients with no complications stayed longer than average (15 days or more). This was unlikely to have been influenced by the in-hospital mortality rate of 1.3 per cent (9 of 672). Endoscopic therapy constituted a small proportion of the resources used for the sample, with 220 procedures in total with the majority of these for endoscopic stent placement (Tables 1 and 2).

$+B:$ Costs

Applying unit costs for each resource type (Table S2, supporting information), overall mean costs were estimated as €17 281 (median €13 066) for the non-surgical group and €37 195 (median €29 114) for patients who underwent surgical management (Table 4), of which €24 697 was for the actual surgical episode. Total costs related to the overall patient cohort with a mean survival of 28.9 (i.q.r. 11.5-44.9) months. Among patients who had surgical management, primary surgical costs represented the highest share (66.4 per cent) of total costs followed by chemotherapy (20.8 per cent) and radiation therapy (3.5 per cent). Among patients who underwent non-surgical management, chemotherapy comprised 61.1 per cent of costs followed by radiation (15.8 per cent) and investigations after initial adjuvant therapies (8.1 per cent). For both surgical and non-surgical cases, costs rose sharply during the first 3 months and increased gradually thereafter.

$+B$ : Univariable analysis

$+\mathrm{C}$ : Non-surgical group 
For non-surgical patients, mean costs were higher for individuals with gastro-oesophageal junction tumours (€24 762 versus $€ 16169$ for oesophageal adenocarcinoma; $P=0.007$ ), for those who received any chemotherapy (€20 030 versus $€ 4626$ for no chemotherapy; $P<0.001$ ), for any radiotherapy (€18 107 versus $€ 13657$ for no radiation; $P=0.024$ ) and for patients aged less than 65 years ( $€ 18986$ versus $€ 15922$ for those aged 65 years or more; $P=0.053$ ). Costs were not significantly associated with sex, cancer stage, smoking status, being monitored for Barrett's oesophagus, co-morbidity or household income (Table S3, supporting information).

\section{$+\mathrm{C}$ : Surgical group}

For individuals who underwent surgery, higher costs were incurred for patients with stage III disease ( $€ 40935$ versus $€ 32660$ in those with stage I disease; $P=0.002$ ). Costs for stages II and IV were not significantly different from those for stage I. Similar to costs for non-surgical cases, costs were also higher for those who received chemotherapy (€42 507 versus $€ 30686$ with no chemotherapy; $P<0.001$ ) or radiotherapy (€40 736 versus $€ 34423$ with no radiation; $P<0.001$ ). Costs were significantly lower for those who had endoscopic surveillance for Barrett's oesophagus (€27 667 versus $€ 38209$ with no surveillance; $P<0.001$ ), and for those living in remote versus metropolitan locations ( $€ 28907$ versus $€ 37650$ respectively; $P=0.001$ ) (Table S4, supporting information).

In both surgical and non-surgical subgroups, mixed results were found for costs by rurality, with no significant differences found between participants living in inner or outer regional areas compared with metropolitan locations. As numbers were very small in the remote and very remote categories, cost figures were unstable, as indicated by the 95 per cent c.i. (Tables S3 and S4, supporting information).

\section{$+B$ : Multivariable analyses}

In multivariable regression analyses, extended survival (in months) was significantly associated with having an oesophagectomy, as well as endoscopic surveillance of Barrett's oesophagus, whereas shorter survival was associated with more advanced tumour stage and tumour location at the gastro-oesophageal junction (Table S5, supporting information). Where costs for individuals were fully observed (uncensored), mean costs were significantly higher for surgical intervention (€41 244), gastro-oesophageal junction tumour location ( $€ 37$ 398), chemotherapy (€31 095) and treatment delivered in Victoria (€37 821). When costs were censored, mean costs were significantly higher for surgical intervention (€32 143), chemotherapy (€32 942) and stage 
III tumours (€47 680), and lower for those undergoing endoscopic surveillance for Barrett’s oesophagus ( $€ 24553)(P=0.082)$. Considering these two cost regression models together, after taking into account the high cost of surgical intervention, chemotherapy, tumour location and treatment location remained strong influences on medical costs in this cohort. The three-part regression model performed well according to standard statistical checks (Table S5, supporting information).

\section{+A: Discussion}

A comprehensive overview has been provided of the major practice patterns, interactions between the natural history and management of oesophageal cancer, and associated healthcare resources employed in a large patient cohort from multiple settings. Overall, the majority of patients with oesophageal cancer presented with stage II, III or IV disease, and 61.1 per cent (672 of 1100) of patients had surgical treatment. The main determinants of costs were the resources involved in the surgical episode for surgically treated patients, and chemotherapy for patients not undergoing surgery. Other important determinants of high costs were gastrooesophageal junction tumours, treatment location, tumour stage and radiotherapy. Costs were substantially lower for the 7.3 per cent of patients who had endoscopic surveillance for Barrett's oesophagus.

Analysis of the ACS CFU data provides a better understanding of the current patterns of care and their interaction with natural history over the course of oesophageal cancer. In doing so, this study has provided a foundation for modelling comparative outcomes, resource use and costeffectiveness of alternative technologies, management pathways and strategies relative to current practice $^{7-9}$. For example, any treatments that can substitute for oesophagectomy with equal efficacy in the treatment of oesophageal cancer, or eliminate adverse events and reduce length of hospital stay, are likely to reduce initial resource outlays significantly. Conversely, with latestage care, new chemotherapeutic agents are unlikely to be cost-effective unless they are inexpensive and have substantial health gains, especially as the main chemotherapeutic agents used for the treatment of oesophageal cancer, 5-fluorourcil and cisplatin, are relatively inexpensive. Patients with stage I disease had significantly lower costs compared with patients presenting with more advanced disease, suggesting that detection strategies that allow earlier treatment of oesophageal cancer might extend survival prospects and reduce overall treatment 
costs. It is important to note that the treatment costs were estimated with the full range of presentations of patients with oesophageal cancer. Although this study found that patients in surveillance programmes presented with earlier stage tumours and incurred fewer treatment costs, this does not lead to the conclusion that surveillance is a cost-effective strategy. To make such a claim, it would be necessary to assess the total costs of surveillance, including the costs of following up all of the people who did not develop cancer. The main value of the present study is its detailed assessment of a wide range of resources employed throughout the disease course; by this means it has provided an accurate view of healthcare costs and the main cost determinants for oesophageal cancer.

Several other studies have examined resource utilization and costs among individuals with oesophageal cancer ${ }^{4,29,30}$. In a 2001 cross-sectional study from the USA by Soni and Sonnenberg ${ }^{4}$, analysis was undertaken on resource utilization and costs for 29 patients with oesophageal adenocarcinoma from a single centre. The present study verifies these findings by also showing that very high costs were incurred overall but with wide variation. A Taiwainese study by Hsieh and Chien ${ }^{29}$ in 2009 assessed costs by disease stage over a long time interval and concluded that surgery and stage were the most influential factors in predicting high costs. In 2009, Polinder et al. ${ }^{30}$ studied the costs of nursing follow-up care over 12 months and concluded that nurse-led care achieved cost savings compared with standard follow-up, although the differences in this study were not statistically significant. The present data are likely to be more robust, for several reasons. First, a much larger patient cohort was incorporated and this enabled three cancer subtypes to be evaluated with sufficient power for multivariable regression analysis. Second, a wide range of resources throughout the disease course was covered. Third, methods addressing right-skewed and right-censored data were used.

The present study has some limitations in coverage of all potential treatments and resource use. Treatments and resources used for side-effects from chemotherapy or radiation treatment were not collected, and neither were data on family practitioner visits, proton pump inhibitor medications or costs relating to end-of-life healthcare where they were incurred outside hospital. These additional costs are likely to be orders of magnitude lower than those for surgery, radiotherapy and chemotherapy, although the present study did not address this. A recent Australian study estimated the costs of ovarian cancer treatment in a cohort of 85 women over 2.5 years and found additional mean costs of \$23 040 (AUD 2008) per patient treated for 
complications while receiving chemotherapy ${ }^{31}$. Overall, with the exception of stage data, the proportion of missing data was negligible. Tumour stage was not recorded in the case notes for nearly half of the patients; however, American Joint Committee on Cancer stage was imputed using regression methods to minimize the potential bias of this on study findings. Some data gaps are inevitable because the study depended on the quality of clinical records for each participant. However, every effort was made to reduce these errors with case-form auditing and training of research nurses before and during the study. None of the participants with early-stage cancers had endoscopic mucosal resection, a relatively new procedure that is a less invasive alternative to oesophagectomy. Endoscopic treatment of early-stage intramucosal disease was not allowed. If endoscopic treatments were to become routine for the very early stage of these cancers, total costs would be expected to be lower in these populations if the duration of hospital stay were shortened and/or fewer postoperative complications arose. However, this assumption is currently untested.

The profile of study participants matched closely that of other Western populations with oesophageal cancer - predominantly male Caucasians aged in their mid-sixties ${ }^{1}$. However, in generalizing results to the total patient population, it should be noted that recruitment was largely via notifications from upper gastrointestinal surgeons and gastroenterologists, and patients aged over 80 years were excluded. Patients over 80 years of age are usually managed by non-surgical treatment, and some patients referred directly to medical oncologists and radiotherapists for palliative treatment may have been missed. Hence, the proportion of patients who were relatively well and had earlier stage cancers was probably higher than in the overall population.

Nevertheless, the present assessment of specific costs of surgical versus non-surgical treatment is still likely to be valid and representative of these treatment pathways. In addition, resource use has been presented separately before applying unit prices, allowing costs to be estimated in other jurisdictions that apply their own pricing schedules. The evidence of relative treatment cost from Australia should translate well to the UK and mainland Europe, given similar publicly funded universal healthcare systems, populations and relative prices (for example, the cost of endoscopy will be significantly higher than that of chest X-ray in both settings), and the use of purchasing power parities in exchange rate conversion. Ultimately, the data and analysis presented will be most useful in economic modelling studies of new technologies for managing oesophageal cancer where detailed cost and resource estimates are required. 


\section{Contributors}

The following contributed to the Australian Cancer Study Clinical Follow-Up Study. Investigators: D. C. Whiteman, A. C. Green, D. Gotley, B. M. Smithers, D. I. Watson, G. L. Falk, G. Smith, G. Kiroff, S. Archer, N. K. Hayward, A. Clouston. Project managers: T. Corish, S. Moore. Database: K. Harrap, T. Sadkowski. Research nurses: J. Thomas, E. Minehan, D. Roffe, S. O’Keefe, S. Lipshut, G. Connor, H. Berry, L. Terry, M. Connard, L. Bowes, M. R. Malt, J. White. Clinical contributors: C. Mosse, N. Tait (Australian Capital Territory); C. Bambach, A. Biankan, R. Brancatisano, M. Coleman, M. Cox, S. Deane, J. Gallagher, M. Hollands, T. Hugh, D. Hunt, J. Jorgensen, C. Martin, M. Richardson, R. Smith, D. Storey (New South Wales); J. Avramovic, J. Croese, J. D'Arcy, S. Fairley, J. Hansen, J. Masson, I. Martin, L. Nathanson, B. O'Loughlin, L. Rutherford, R. Turner, M. Windsor (Queensland); D. Watson, J. Bessell, P. Devitt, G. Jamieson (South Australia); S. Blamey, A. Boussioutas, R. Cade, G. Crosthwaite, I. Faragher, J. Gribbin, G. Hebbard, B. Mann, B. Millar, P. O'Brien, R. Thomas, S. Wood (Victoria); K. Faulkner, J. Hamdorf (Western Australia).

\section{Acknowledgements}

The authors sincerely thank the men and women in the study who devoted their time to take part in the research. They thank Ian Bishop, Vivienne Lloyd and Adrian McCrystal from the Royal Brisbane and Women’s Hospital, and the Royal Children’s Hospital Casemix and Clinical Costing Department for their assistance with unit costs for various medical procedures.

This study was supported by the Cancer Council Queensland and the National Health and Medical Research Council (NHMRC) of Australia (Programme no. 199600; Project 389820). D.C.W. is funded by an Australian Research Council Future Fellowship. L.G.G. is funded by a NHMRC Public Health Training Fellowship (no. 496714). N.G.H. is funded by a NHMRC

Programme Grant (no. 552429). The authors declare no conflict of interest.

\section{References}

1 Brown LM, Devesa SS, Chow WH. Incidence of adenocarcinoma of the esophagus among white Americans by sex, stage, and age. J Natl Cancer Inst 2008; 100: 1184-1187. 2 Stavrou EP, McElroy HJ, Baker DF, Smith G, Bishop JF. Adenocarcinoma of the oesophagus: incidence and survival rates in New South Wales, 1972-2005. Med J Aust 2009; 191: 310-314.

3 Epari K, Cade RJ. Oesophagectomy for tumours and dysplasia of the oesophagus and gastro-oesophageal junction. ANZ J Surg 2009; 79: 251-257. 
4 Soni A, Sonnenberg A. Healthcare resource utilization in the management of oesophageal adenocarcinoma. Aliment Pharmacol Ther 2001; 15: 945-951.

$5 \quad$ Wilson LS, Tesoro R, Elkin EP, Sadetsky N, Broering JM, Latini DM et al. Cumulative cost pattern comparison of prostate cancer treatments. Cancer 2007; 109: 518-527.

$6<\mathrm{B}>$ Australian Institute of Health and Welfare (AIHW). Health System Expenditures on Cancer and Other Neoplasms in Australia, 2000-01. Australian Institute of Health and Welfare: Canberra, 2005.

7 Moss A, Bourke MJ, Hourigan LF, Gupta S, Williams SJ, Tran K et al. Endoscopic resection for Barrett's high-grade dysplasia and early esophageal adenocarcinoma: an essential staging procedure with long-term therapeutic benefit. Am J Gastroenterol 2010; 105: 12761283.

8 Shaheen N, Sharma P, Overholt BF, Wolfsen HC, Sampliner R, Wang G et al. Radiofrequency ablation in Barrett's esophagus with dysplasia. N Engl J Med 2009; 360: 22772288.

9 Wolfsen HC. New technologies for imaging of Barrett's esophagus. Surg Oncol Clin N Am 2009; 18: 487-502.

10 McKoy JM, Fitzner KA, Edwards BJ, Alkhatib M, Tigue CC, Nonzee NJ et al. Cost considerations in the management of cancer in the older patient. Oncology (Williston Park) 2007; 21: 851-857.

11 Shih YC, Halpern MT. Economic evaluations of medical care interventions for cancer patients: how, why, and what does it mean? CA Cancer J Clin 2008; 58: 231-244.

12 Eckermann S, Coory M, Willan AR. Consistently estimating absolute risk difference when translating evidence to jurisdictions of interest. Pharmacoeconomics 2011; 29: 87-96.

13 Eckermann S, Coory M, Willan AR. Consistently estimating risk difference in a jurisdiction of interest: odds solution to relative risk fallacies. Value in Health 2010; 11: A577A578 (Abstract).

14 Hirst NG, Gordon LG, Whiteman DC, Watson DI, Barendregt JJ. Is endoscopic surveillance for non-dysplastic Barrett's esophagus cost-effective? Review of economic evaluations. J Gastroenterol Hepatol 2011; 26: 247-254.

15 Whiteman DC, Sadeghi S, Pandeya N, Smithers BM, Gotley DC, Bain CJ et al. Combined effects of obesity, acid reflux and smoking on the risk of adenocarcinomas of the oesophagus. Gut 2008; 57: 173-180.

$16<$ EPATH $>$ Department of Health and Ageing. Guidelines for preparing submissions to the Pharmaceutical Benefits Advisory Committee (Version 4.3). Department of Health and Ageing, Australian Government: Canberra, 2008.

http://www.health.gov.au/internet/main/publishing.nsf/content/pbacguidelines-index [accessed 1 September 2010].

$17<$ EPATH $>$ Department of Health and Ageing. National Hospital Cost Data Collection, Round 13, Cost Report Public (Version 5.1). Department of Health and Ageing, Australian Government: Canberra, 2010.

http://www.health.gov.au/internet/main/publishing.nsf/Content/health-casemix-data-collectionsabout [accessed 1 September 2010].

$18<\mathrm{B}>$ Department of Health and Ageing. Schedule of Pharmaceutical Benefits for Approved Pharmacists and Medical Practitioners, Chemotherapy Pharmaceuticals Access Program Supplement. Department of Health and Ageing, Australian Government: Canberra, 2008. 
$19<$ EPATH>Department of Health and Ageing. MBS Online, Medicare Benefits Schedule Update. http://www9.health.gov.au/mbs/search.cfm [accessed 1 November 2007].

20 Briggs A, Clark T, Wolstenholme J, Clarke P. Missing... presumed at random: costanalysis of incomplete data. Health Econ 2003; 12: 377-392.

21 Australian Institute of Health and Welfare (AIHW). Health Expenditure in Australia, 2004-05. Australian Institute of Health and Welfare: Canberra, 2006.

$22<$ EPATH $>$ Organisation for Economic Co-operation and Development. Purchasing

Power Parities (PPP) June 2007. http://www.oecd.org/std/ppp [accessed 1 August 2007].

23 Doshi JA, Glick HA, Polsky D. Analyses of cost data in economic evaluations conducted alongside randomized controlled trials. Value in Health 2006; 9: 334-340.

$24<$ B $>$ Efron B, Tibshirani RJ. An Introduction to the Bootstrap. Chapman and Hall: New York, 1993.

$25<$ B $>$ Drummond MF, Sculpher MJ, Torrance GW, O'Brien BJ, Stoddard GL. Methods for the Economic Evaluation of Health Care Programmes (3rd edn). Oxford University Press: Oxford, 2005.

26 Basu A, Manning WG. Estimating lifetime or episode-of-illness costs under censoring. Health Econ 2010; 19: 1010-1028.

27 Basu A. Extended generalized linear models: simultaneous estimation of flexible link and variance functions. The Stata Journal 2005; 5: 501-516.

$28<\mathrm{B}>$ Jones AM. Models for Health Care. Health, Econometrics and Data Group (HEDG) Working Paper 10/01. University of York: York, 2010.

29 Hsieh CC, Chien CW. A cost and benefit study of esophagectomy for patients with esophageal cancer. J Gastrointest Surg 2009; 13: 1806-1812.

30 Polinder S, Verschuur EM, Siersema PD, Kuipers EJ, Steyerberg EW. Cost comparison study of two different follow-up protocols after surgery for oesophageal cancer. Eur J Cancer 2009; 45: 2110-2115.

31 Gordon LG, Scuffham PA, Beesley VL, Green AC, DeFazio A, Wyld DK et al. Medical costs and outcomes for Australian women with ovarian cancer. Int J Gynecol Cancer 2010; 20: 757-765. 


\section{Supporting information}

Additional supporting information may be found in the online version of this article:

Table S1 Baseline sociodemographic and disease characteristics of surgical and non-surgical patients (Word document)

Table S2 Resource unit costs (€ 2009) and sources (Word document)

Table S3 Bootstrapped mean total costs (€ 2009) by subgroups for 426 patients managed without surgery (Word document)

Table S4 Bootstrapped mean total costs (€ 2009) by subgroups for 672 patients managed by surgery (Word document)

Table S5 Results of three-part multivariable regression analysis (Word document)

Please note: John Wiley \& Sons Ltd is not responsible for the functionality of any supporting materials supplied by the authors. Any queries (other than missing material) should be directed to the corresponding author for the article. 
Table S1 Baseline sociodemographic and disease characteristics of surgical and non-surgical patients

\begin{tabular}{|c|c|c|}
\hline & Non-surgical patients $(n=426)$ & Surgical patients $(n=672)$ \\
\hline Mean(s.d.) age (years) & $65.0(9.6)$ & $62.9(9.5)$ \\
\hline \multicolumn{3}{|l|}{ Age category (years) $\dagger$} \\
\hline$\geq 65$ & $237(55.6)$ & $313(46.6)$ \\
\hline$<65$ & $189(44.4)$ & $359(53.4)$ \\
\hline \multicolumn{3}{|l|}{ Sex } \\
\hline $\mathrm{F}$ & $93(21.8)$ & 130 (19.3) \\
\hline M & $333(78.2)$ & $541(80.5)$ \\
\hline missing & & $1(0.1)$ \\
\hline \multicolumn{3}{|l|}{ Educational level } \\
\hline School & 199 (46.7) & $299(44.5)$ \\
\hline Trade/certificate/diploma & $163(38.3)$ & 302 (44.9) \\
\hline Bachelor degree & 39 )9.2) & $52(7.7)$ \\
\hline Missing & $25(5.9)$ & $19(2.8)$ \\
\hline \multicolumn{3}{|l|}{ Marital status $\dagger$} \\
\hline Never married & $28(6.6)$ & $20(3.0)$ \\
\hline Married/living together & $284(66.7)$ & $523(77.8)$ \\
\hline Separated/divorced/widowed & $82(19.2)$ & $106(15.8)$ \\
\hline Missing & $32(7.5)$ & $23(3.4)$ \\
\hline \multicolumn{3}{|l|}{ Rurality } \\
\hline Major city & 255 (59.9) & 399 (59.4) \\
\hline Inner regional & $94(22.1)$ & 167 (24.9) \\
\hline Outer regional & $48(11.3)$ & 71 (10.6) \\
\hline Remote or very remote & $13(3.1)$ & $10(1.5)$ \\
\hline Missing & $16(3.8)$ & $25(3.7)$ \\
\hline \multicolumn{3}{|l|}{ State } \\
\hline New South Wales & $102(23.9)$ & 199 (29.6) \\
\hline Queensland & 136 (31.9) & $218(32.4)$ \\
\hline South Australia & 49 (11.5) & $80(12.0)$ \\
\hline Victoria & $86(20.2)$ & $121(18.0)$ \\
\hline Western Australia & $52(12.2)$ & $54(8.0)$ \\
\hline Missing & $1(0.2)$ & \\
\hline \multicolumn{3}{|l|}{ Ethnicity } \\
\hline Caucasian & $387(90.8)$ & $640(95.2)$ \\
\hline Other & $13(3.1)$ & $13(1.9)$ \\
\hline Missing & $26(6.1)$ & $19(2.8)$ \\
\hline \multicolumn{3}{|l|}{ Employment status (1 year earlier) } \\
\hline Full-time & $110(25.8)$ & $209(31.1)$ \\
\hline Part-time & $29(6.8)$ & $58(8.6)$ \\
\hline Disability pension & $16(3.8)$ & $18(2.7)$ \\
\hline Not working & $230(56.3)$ & $350(51.8)$ \\
\hline Unemployed & $7(1.6)$ & $7(1.0)$ \\
\hline Missing & $34(8.0)$ & $30(4.5)$ \\
\hline \multicolumn{3}{|c|}{ Gross annual household income (AUD) } \\
\hline Not stated & $39(9.2)$ & $68(10.1)$ \\
\hline$<45000$ & $243(57.0)$ & 384 (57.1) \\
\hline $45000-79000$ & $71(16.7)$ & 138 (20.5) \\
\hline$\geq 80000$ & $48(11.3)$ & $63(9.4)$ \\
\hline Missing & $25(5.9)$ & $19(2.8)$ \\
\hline \multicolumn{3}{|l|}{ Smoking status $\dagger$} \\
\hline Current smoker & $116(27.2)$ & $153(22.8)$ \\
\hline Ex-smoker & 199 (46.7) & 319 (47.5) \\
\hline Never smoked & $83(19.5)$ & $178(26.5)$ \\
\hline Missing & $28(6.6)$ & $22(3.3)$ \\
\hline
\end{tabular}




\begin{tabular}{lcc}
\hline Co-morbid conditions* & & \\
None & $50(11.7)$ & $52(7.7)$ \\
1 & $135(31.7)$ & $187(27.8)$ \\
$\geq 2$ & $241(56.6)$ & $433(64.4)$ \\
\hline Cancer type $\dagger$ & & \\
Squamous cell cancer of oesophagus & $180(42.3)$ & $125(18.6)$ \\
Gastro-oesophageal junction adenocarcinoma & $72(16.9)$ & $353(52.5)$ \\
Oesophageal adenocarcinoma & $173(40.6)$ & $194(28.9)$ \\
Missing & $1(0.2)$ & $0(0)$ \\
\hline AJCC stage $\dagger$ & & \\
I & $11(2.6)$ & $54(8.0)$ \\
II & $44(10.3)$ & $152(22.6)$ \\
III & $39(9.2)$ & $123(18.3)$ \\
IV & $115(27.0)$ & $26(3.9)$ \\
Unknown & $217(50.9)$ & $317(47.2)$ \\
\hline Monitored for Barrett's oesophagus $\dagger$ & & \\
No & $405(95.1)$ & $597(88.8)$ \\
Yes & $15(3.5)$ & $64(9.5)$ \\
Missing & $6(1.4)$ & $11(1.6)$ \\
\hline Vas
\end{tabular}

Values in parentheses are percentages. AUD, Australian dollars; AJCC, American Joint Committee on Cancer. *Comorbid conditions included diabetes mellitus type I or II, Barrett’s oesophagus, oesophagitis, gastritis, pancreatitis, ulcer, hernia, irritable bowel syndrome, diverticulitis, gallstones, bulimia, and breast, ovarian, stomach and colonic cancer. $\uparrow P<0.050$ (non-surgical versus surgical patients, Wald test). 
Table S2 Resource unit costs ( $€$ 2009) and sources

\begin{tabular}{|c|c|c|c|}
\hline & Unit & Unit cost $(€)$ & Source \\
\hline \multicolumn{4}{|l|}{ Endoscopic therapy } \\
\hline Argon plasma coagulation & \multirow{4}{*}{$\begin{array}{c}\text { Per } \\
\text { procedure }\end{array}$} & 204 & Shenfine 2009 \\
\hline Photodynamic therapy & & 113 & RBWH \\
\hline Endoscopic laser therapy & & 204 & Shenfine 2009 \\
\hline Endoscopic stent placement & & 2761 & Flinders Medical Centre \\
\hline \multicolumn{4}{|l|}{ Surgery } \\
\hline Median length of stay 15.5 days & \multirow{2}{*}{$\begin{array}{c}\text { Sample } \\
\text { mean(s.d.) } \\
\text { of mean per } \\
\text { episode }\end{array}$} & \multirow[b]{2}{*}{ 1318(877) } & \\
\hline Median (range) \$2429 (649-8203) & & & $\begin{array}{c}\text { Based on RBWH sample with AR- } \\
\text { DRGs G03A, G42A, G60A }\end{array}$ \\
\hline \multicolumn{4}{|l|}{$\begin{array}{l}\text { Chemotherapy agents (5 most } \\
\text { common) }\end{array}$} \\
\hline 5-Fluorouracil & \multirow{3}{*}{ Per mg } & 0.0060 & \multirow{4}{*}{$\begin{array}{c}\text { Chemotherapy Pharmaceuticals } \\
\text { Access Program }\end{array}$} \\
\hline Cisplatin & & 0.3160 & \\
\hline Epirubicin hydrochloride & & 2.4985 & \\
\hline Carboplatin & \multirow[b]{2}{*}{ Per day } & 0.1419 & \\
\hline $\begin{array}{l}\text { Chemotherapy } \\
\text { delivery/administration }\end{array}$ & & 433 & RBWH \\
\hline Radiotherapy & Per day & 125 & Flinders Medical Centre \\
\hline \multicolumn{4}{|l|}{ Investigations } \\
\hline Endoscopy (60 min) & \multirow{16}{*}{$\begin{array}{c}\text { Per } \\
\text { procedure }\end{array}$} & 485 & RBWH \\
\hline Endoscopic ultrasonography & & 562 & RBWH \\
\hline Computed tomography & & 276 & RBWH \\
\hline Abdominal X-ray & & 36 & RBWH \\
\hline Barium meal & & 64 & RBWH \\
\hline Blood test & & 9 & RBWH \\
\hline Whole-body bone scan/PET & & 482 & RBWH \\
\hline Bronchoscopy (60 min) & & 182 & RBWH \\
\hline Chest X-ray & & 38 & RBWH \\
\hline Electrocardiography & & 13 & RBWH \\
\hline Fine-needle aspiration & & 362 & RBWH \\
\hline Laparoscopy & & 203 & MBS $30391+20706$ \\
\hline Magnetic resonance imaging & & 232 & MBS 63204 \\
\hline Other X-ray & & 36 & RBWH \\
\hline Biopsy & & 337 & RBWH \\
\hline Ultrasonography & & 68 & RBWH \\
\hline \multicolumn{4}{|l|}{ Other concurrent investigations } \\
\hline Electrocardiography & & 59 & MBS 11000 \\
\hline Intravenous pyelography & & 443 & RBWH \\
\hline ERCP & & 79 & RBWH \\
\hline
\end{tabular}


Angiography

Colonoscopy (60 min)

Echocardiography

Other procedures

Pleurodesis

Drainage tap of collection
365

464

167

459

362
RBWH

RBWH

RBWH

MBS 38424

RBWH

RBWH, Royal Brisbane and Women’s Hospital; AR-DRG, Australian refined diagnosis-related group; PET, positron emission tomography; MBS, Medicare Benefits Schedule; ERCP, endoscopic retrograde cholangiopancreatography.

Shenfine J, McNamee P, Steen N, Bond J, Griffin SM. A randomized controlled clinical trial of palliative therapies for patients with inoperable esophageal cancer. Am J Gastroenterol. 2009 Jul;104(7):1674-85. 
Table S3 Bootstrapped mean total costs (€ 2009) by subgroups for 426 patients managed without surgery

\begin{tabular}{|c|c|c|c|}
\hline & Mean total cost $(€)$ & Wald statistic & $P^{*}$ \\
\hline \multicolumn{4}{|l|}{ AJCC stage } \\
\hline $\mathrm{I}$ & $16102(10$ 662, 21 542) & Reference & \\
\hline II & $17885(15$ 175, 20 596) & 0.33 & 0.566 \\
\hline III & 15349 (13 203, 17 494) & 0.06 & 0.803 \\
\hline IV & $18820(15$ 604, 22 037) & 0.70 & 0.404 \\
\hline \multicolumn{4}{|l|}{ Monitored for Barrett's oesophagus } \\
\hline No & $17344(15$ 785, 18 903) & Reference & \\
\hline Yes & $14691(8812,20569)$ & 0.73 & 0.394 \\
\hline \multicolumn{4}{|l|}{ Cancer subtype } \\
\hline Oesophageal adenocarcinoma & $16169(13833,18$ 506) & Reference & \\
\hline Gastro-oesophageal junction adenocarcinoma & $24762(18953,30$ 571) & 7.24 & 0.007 \\
\hline Squamous cell carcinoma & $15398(13$ 842, 16 954) & 0.28 & 0.594 \\
\hline \multicolumn{4}{|l|}{ Radiotherapy } \\
\hline No & $13657(10$ 098, 17 216) & Reference & \\
\hline Yes & 18107 (16 406, 19 807) & 5.07 & 0.024 \\
\hline \multicolumn{4}{|l|}{ Chemotherapy } \\
\hline No & $4626(4037,5215)$ & Reference & \\
\hline Yes & $20030(18$ 257, 21 803) & 258.06 & $<0.001$ \\
\hline \multicolumn{4}{|l|}{ State } \\
\hline New South Wales & 15627 (12 648, 18 606) & Reference & \\
\hline Queensland & 15684 (13 506, 17 862) & 0.00 & 0.976 \\
\hline South Australia & 13749 (11 284, 16 214) & 0.93 & 0.335 \\
\hline Victoria & 22409 (17 540, 27 278) & 5.16 & 0.023 \\
\hline Western Australia & 19691 (15 862, 23 521) & 2.73 & 0.098 \\
\hline \multicolumn{4}{|l|}{ Sex } \\
\hline $\mathrm{F}$ & 15929 (13 197, 18 659) & Reference & \\
\hline M & $18012(16046,19978)$ & 1.44 & 0.231 \\
\hline \multicolumn{4}{|l|}{ Age category (years) } \\
\hline$\geq 65$ & 15922 (13 819, 18 025) & Reference & \\
\hline$<65$ & $18986(16$ 654, 21 318) & 3.76 & 0.053 \\
\hline \multicolumn{4}{|l|}{ Smoking status } \\
\hline Current smoker & 16348 (13 790, 18 905) & Reference & \\
\hline Ex-smoker & 18127 (15 567, 20 686) & 0.95 & 0.330 \\
\hline Non-smoker & $17342(13$ 744, 20 940) & 0.12 & 0.730 \\
\hline \multicolumn{4}{|l|}{ Household income (AUD) } \\
\hline Not stated & 19587 (14 261, 24 913) & & \\
\hline$<45000$ & $16677(14$ 570, 18 783) & Reference & \\
\hline $45000-79000$ & 18340 (14 770, 21 909) & 0.62 & 0.430 \\
\hline$\geq 80000$ & 19320 (14 088, 24 552) & 0.89 & 0.346 \\
\hline
\end{tabular}

No. of co-morbidities 


\begin{tabular}{llll}
0 & $16214(12409,20020)$ & Reference & \\
1 & $16882(14349,19416)$ & 0.08 & 0.779 \\
$\geq 2$ & $17726(15519,19934)$ & 0.45 & 0.502 \\
\hline Rurality & & & \\
Major city & $17065(15162,18979)$ & Reference & \\
Inner regional & $19608(15539,23677)$ & 1.21 & 0.272 \\
Outer regional & $13616(10575,16$ 658) & 3.52 & 0.061 \\
Remote & $15263(10902,19624)$ & 0.57 & 0.451 \\
Very remote & $28748(18346,39149)$ & 4.68 & 0.031 \\
\hline
\end{tabular}

Values in parentheses are 95 per cent confidence intervals. AJCC, American Joint Committee on Cancer; AUD, Australian dollars. Wald test. 
Table S4 Bootstrapped mean total costs (€ 2009) by subgroups for 672 patients managed by surgery

\begin{tabular}{|c|c|c|c|}
\hline & Mean total cost $(€)$ & Wald statistic & $P^{*}$ \\
\hline \multicolumn{4}{|l|}{ AJCC stage } \\
\hline $\mathrm{I}$ & $32660(28$ 518, 36 802) & Reference & \\
\hline II & 35621 (33 141, 38 103) & 1.41 & 0.234 \\
\hline III & 40935 (37 693, 44 177) & 9.79 & 0.002 \\
\hline IV & 37537 (32 755, 42 319) & 2.29 & 0.130 \\
\hline \multicolumn{4}{|l|}{ Monitored for Barrett’s oesophagus } \\
\hline No & 38209 (36 322, 40 096) & Reference & \\
\hline Yes & $27667(24$ 133, 31 201) & 24.92 & $<0.001$ \\
\hline \multicolumn{4}{|l|}{ Cancer subtype } \\
\hline Oesophageal adenocarcinoma & 36695 (33 803, 39 589) & Reference & \\
\hline Gastro-oesophageal junction adenocarcinoma & 38039 (35 475, 40 604) & 0.50 & 0.450 \\
\hline Squamous cell carcinoma & 35582 (32 016, 39 149) & 0.22 & 0.637 \\
\hline \multicolumn{4}{|l|}{ Radiotherapy } \\
\hline No & 34423 (32 084, 36 762) & Reference & \\
\hline Yes & $40736(38$ 137, 43 335) & 12.87 & $<0.001$ \\
\hline \multicolumn{4}{|l|}{ Chemotherapy } \\
\hline No & 30686 (28 226, 33 146) & Reference & \\
\hline Yes & $42507(40$ 228, 44 786) & 47.81 & $<0.001$ \\
\hline \multicolumn{4}{|l|}{ State } \\
\hline New South Wales & 35321 (32 446, 38 198) & Reference & \\
\hline Queensland & 32582 (30 214, 34 951) & 2.19 & 0.139 \\
\hline South Australia & 39969 (34 348, 45 590) & 2.12 & 0.146 \\
\hline Victoria & 45328 (40 251, 50 405) & 11.81 & $<0.001$ \\
\hline Western Australia & 40377 (33 826, 46 928) & 1.94 & 0.164 \\
\hline \multicolumn{4}{|l|}{ Sex } \\
\hline $\mathrm{F}$ & 36872 (32 898, 40 846) & Reference & \\
\hline M & 37029 (35 045, 39 012) & 0.00 & 0.945 \\
\hline \multicolumn{4}{|l|}{ Age category (years) } \\
\hline$\geq 65$ & 36183 (33 701, 38 667) & Reference & \\
\hline$<65$ & $38076(35$ 748, 40 404) & 1.18 & 0.277 \\
\hline \multicolumn{4}{|l|}{ Smoking status } \\
\hline Current smoker & 38117 (34 723, 41 510) & Reference & \\
\hline Ex-smoker & 37245 (34 766, 39 724) & 0.17 & 0.680 \\
\hline Non-smoker & 35777 (32 296, 39 258) & 0.87 & 0.352 \\
\hline \multicolumn{4}{|l|}{ Household income (AUD) } \\
\hline Not stated & 33429 (29 634, 37 223) & & \\
\hline$<45000$ & 37353 (35 050, 39 655) & Reference & \\
\hline $45000-79000$ & 36403 (31 971, 40 835) & 0.14 & 0.707 \\
\hline$\geq 80000$ & 39992 (35 063, 44 920) & 0.91 & 0.340 \\
\hline
\end{tabular}

No. of co-morbidities 


\begin{tabular}{llll}
0 & $38817(33665,43968)$ & Reference & \\
1 & $39307(36038,42576)$ & 0.03 & 0.870 \\
$\geq 2$ & $36087(33971,38203)$ & 0.91 & 0.340 \\
\hline Rurality & & & \\
Major city & $37650(35$ 467, 39 832) & Reference & \\
Inner regional & $36380(33031,39728)$ & 0.40 & 0.527 \\
Outer regional & $36348(30014,42682)$ & 0.15 & 0.701 \\
Remote & $28907(24461,33$ 352) & 12.58 & 0.001 \\
Very remote & $54007(22984,85030)$ & 1.06 & 0.304 \\
\hline
\end{tabular}

Values in parentheses are 95 per cent confidence intervals. AJCC, American Joint Committee on Cancer; AUD, Australian dollars. Wald test. 
Table S5 Results of three-part multivariable regression analysis

\begin{tabular}{lccc}
\hline & $\begin{array}{c}\text { Coefficient for survival } \\
(n=1037) \text { (gamma } \\
\text { regression accelerated } \\
\text { failure-time) }\end{array}$ & $\begin{array}{c}\text { Coefficient for uncensored } \\
\text { costs }(n=685) \text { (gamma } \\
\text { GLM square-root link) }\end{array}$ & $\begin{array}{c}\text { Coefficient for censored } \\
\text { costs }(n=352) \text { (extended } \\
\text { estimating equation) }\end{array}$ \\
\hline Oesophagectomy & $0.73(0.6,0.9)$ & $121.9(109.2,134.6)$ & $0.57(0.4,0.7)$ \\
AJCC stage II & $-0.16(-0.4,0.1)$ & $8.5(-9.8,26.8)$ & $0.07(-0.0,0.2)$ \\
AJCC stage III & $-0.38(-0.6,-0.2)$ & $1.5(-16.4,19.4)$ & $0.07(-0.0,0.2)$ \\
AJCC stage IV & $-0.71(-1.0,-0.5)$ & $5.5(-13.7,24.7)$ & $0.08(-0.1,0.2)$ \\
Gastro-oesophageal & $-0.23(-0.4,-0.1)$ & $29.6(13.8,45.4)$ & $0.01(-0.0,0.1)$ \\
junction & & & \\
adenocarcinoma & $0.00(0.0,0.0)$ & $0.05(-0.64,0.73)$ & $0.00(0.0,0.0)$ \\
Age at diagnosis & $0.04(-0.1,0.2)$ & $72.9(60.8,85.0)$ & $0.37(0.2,0.5)$ \\
Any chemotherapy & $-0.09(-0.3,0.1)$ & $11.8(-1.4,25.0)$ & $-0.08(-0.2,0.0)$ \\
Any radiotherapy & $1.19(0.9,1.5)$ & $12.4(-17.3,42.0)$ & $-0.06(-0.1,0.0)$ \\
Monitored for Barrett's & $0.10(0.0,0.2)$ & $6.9(-3.5,17.3)$ & $-0.03(-0.1,0.0)$ \\
oesophagus & & $7.8(-6.5,22.1)$ & $0.01(-0.1,0.1)$ \\
Co-morbidity $\geq 2$ & $0.08(-0.1,0.3)$ & $-1.4(-13.7,11.0)$ & $-0.03(-0.1,0.0)$ \\
Employed & $0.02(-0.2,0.2)$ & $-5.5(-24.2,13.3)$ & $-0.07(-0.2,0.1)$ \\
State - Queensland & $0.02(-0.2,0.3)$ & $28.5(6.7,50.2)$ & $0.03(-0.1,0.1)$ \\
State - South Australia & $0.17(-0.0,0.4)$ & $3.7(-14.3,21.8)$ & $0.02(0.0,0.1)$ \\
State - Victoria & $0.04(-0.2,0.3)$ & & \\
State - Western & & & \\
Australia & & & \\
\hline Valyes in par & & & \\
\hline
\end{tabular}

Values in parentheses are 95 per cent confidence intervals. Uncensored refers to data that have been captured for the full duration until the individual's death, whereas censored data are those cut short administratively because the end of the study collection period (31 January 2008) was reached and therefore involve unknown cost data. GLM, generalized linear model; AJCC, American Joint Committee on Cancer. Overall, the regression model for total uncensored costs performed well with a low Akaike Information Criterion (23.7), link test $(P<0.001)$, Pearson's test $(P=0.559)$ and Copas test (coefficient $0.84, P=0.096$ ), indicating no overfitting. Performing just as well, the corresponding results for the censored cost model were Pearson's test $(P=0.288$ ), Copas test (coefficient 0.74 , $P=0.093$ ), and there were no systematic patterns in residuals across the deciles of linear predictors. 
Table 1 Resources used in the diagnosis and management of patients treated surgically for oesophageal cancer by American Joint Committee on Cancer stage*

\begin{tabular}{|c|c|c|c|c|c|c|c|c|c|c|}
\hline & \multicolumn{2}{|c|}{ Stage I ( $n=99)$} & \multicolumn{2}{|c|}{$\begin{array}{l}\text { Stage II } \\
(n=285)\end{array}$} & \multicolumn{2}{|c|}{$\begin{array}{l}\text { Stage III } \\
(n=235)\end{array}$} & \multicolumn{2}{|c|}{ Stage IV $(n=53)$} & \multicolumn{2}{|c|}{ Total $(n=672)$} \\
\hline & $n$ & $\begin{array}{c}\% \\
\text { patients }\end{array}$ & $n$ & $\begin{array}{c}\% \\
\text { patients }\end{array}$ & $n$ & $\begin{array}{c}\% \\
\text { patients }\end{array}$ & $n$ & $\begin{array}{c}\% \\
\text { patients }\end{array}$ & $n$ & $\begin{array}{c}\% \\
\text { patients }\end{array}$ \\
\hline \multicolumn{11}{|l|}{ Diagnostic investigations } \\
\hline Endoscopies† & 99 & 100 & 285 & 100 & 235 & 100 & 53 & 100 & 672 & 100 \\
\hline CT & 93 & 94 & 267 & 93.7 & 214 & 91.1 & 49 & 92 & 623 & 92.7 \\
\hline Endoscopic ultrasonography & 28 & 28 & 57 & 20.0 & 68 & 28.9 & 8 & 15 & 161 & 24.0 \\
\hline PET & 39 & 39 & 126 & 44.2 & 109 & 46.4 & 25 & 47 & 299 & 44.5 \\
\hline Bronchoscopy & 4 & 4 & 6 & 2.1 & 6 & 2.6 & 1 & 2 & 17 & 2.5 \\
\hline Laparoscopy & 18 & 18 & 57 & 20.0 & 59 & 25.1 & 14 & 26 & 148 & 22.0 \\
\hline Other test/procedure $\ddagger$ & 43 & 43 & 138 & 48.4 & 98 & 41.7 & 29 & 55 & 308 & 45.8 \\
\hline Total & 324 & & 936 & & 789 & & 179 & & 2228 & \\
\hline \multicolumn{11}{|l|}{ Chemotherapy§ } \\
\hline Fluorouracil & 856 & 36 & 4582 & 41.1 & 4454 & 40.0 & 1071 & 41 & 10963 & 54.0 \\
\hline Cisplatin & 166 & 35 & 914 & 35.1 & 597 & 31.9 & 242 & 32 & 1919 & 44.9 \\
\hline Epirubicin hydrochloride & 61 & 8 & 417 & 9.1 & 266 & 8.9 & 185 & 8 & 929 & 11.0 \\
\hline Carboplatin & 15 & 2 & 145 & 1.1 & 70 & 1.3 & 27 & 2 & 257 & 1.9 \\
\hline Other & 133 & 15 & 176 & 8.0 & 436 & 14.0 & 47 & 17 & 792 & 23.1 \\
\hline Total & 1231 & 38 & 6234 & 54.0 & 5823 & 60.0 & 1572 & 70 & 14860 & 54.6 \\
\hline Radiotherapy & 145 & 32 & 503 & 35.1 & 663 & 51.9 & 175 & 75 & 1486 & 43.9 \\
\hline $\begin{array}{l}\text { Initial investigations after adjuvant } \\
\text { therapy }\end{array}$ & 51 & 21 & 188 & 31.9 & 218 & 36.2 & 41 & 30 & 498 & 32.0 \\
\hline Surgical inpatient days & 1791 & $15 \#$ & 5139 & $15 \#$ & 4724 & $15 \#$ & 934 & $15 \#$ & 12588 & $15 \#$ \\
\hline Postsurgical investigations & 367 & 87 & 929 & 80.0 & 815 & 82.1 & 133 & 87 & 2244 & 82.0 \\
\hline Subsquent investigations & 94 & 21 & 278 & 26.0 & 289 & 28.9 & 70 & 38 & 731 & 27.0 \\
\hline
\end{tabular}


Endoscopic therapy

Argon plasma coagulation

Photodynamic therapy

Endoscopic stent placement

Endoscopic laser therapy

$\begin{array}{cccccccccc}1 & 1 & 5 & 1.8 & 3 & 1.3 & 1 & 2 & 10 & 1.5 \\ 2 & 2 & 3 & 1.1 & 0 & 0 & 0 & 0 & 5 & 0.7 \\ 7 & 7 & 20 & 7.0 & 14 & 6.0 & 3 & 6 & 44 & 6.5 \\ 0 & 0 & 0 & 0 & 7 & 3.0 & 2 & 4 & 9 & 1.3 \\ 10 & 10 & 28 & 9.8 & 24 & 10.2 & 6 & 11 & 68 & 10.1\end{array}$

*Cancer stage was imputed using regression methods for half the sample where data were missing. †Endoscopy was a condition of entry into the study. $\ddagger$ Includes additional positron emission tomography (PET) or computed tomography (CT) in the diagnostic phase. §Values denote the number of administrations for the four most commonly employed agents; some patients received more than one agent. $\Upsilon$ Values denote number of weeks of radiotherapy. \#Median number of inpatient days. 
Table 2 Resources used in the diagnosis and management of patients not treated surgically for oesophageal cancer by cancer stage*

\begin{tabular}{|c|c|c|c|c|c|c|c|c|c|c|}
\hline & \multicolumn{2}{|c|}{ Stage I $(n=46)$} & \multicolumn{2}{|c|}{$\begin{array}{l}\text { Stage II } \\
(n=133)\end{array}$} & \multicolumn{2}{|c|}{$\begin{array}{l}\text { Stage III } \\
(n=117)\end{array}$} & \multicolumn{2}{|c|}{$\begin{array}{l}\text { Stage IV } \\
(n=130)\end{array}$} & \multicolumn{2}{|c|}{ Total $(n=426)$} \\
\hline & $n$ & $\begin{array}{c}\% \\
\text { patients }\end{array}$ & $n$ & $\begin{array}{c}\% \\
\text { patients }\end{array}$ & $n$ & $\begin{array}{c}\% \\
\text { patients }\end{array}$ & $n$ & $\begin{array}{c}\% \\
\text { patients }\end{array}$ & $n$ & $\begin{array}{c}\% \\
\text { patients }\end{array}$ \\
\hline \multicolumn{11}{|l|}{ Diagnostic investigations } \\
\hline Endoscopy $\dagger$ & 46 & 100 & 133 & 100 & 117 & 100 & 130 & 100 & 426 & 100 \\
\hline CT & 42 & 91 & 124 & 93.2 & 112 & 95.7 & 129 & 99.2 & 407 & 95.5 \\
\hline Endoscopic ultrasonography & 3 & 7 & 21 & 15.8 & 23 & 19.7 & 18 & 13.8 & 65 & 15.3 \\
\hline PET & 17 & 37 & 47 & 35.3 & 51 & 43.6 & 86 & 66.2 & 201 & 47.2 \\
\hline Bronchoscopy & 1 & 2 & 6 & 4.5 & 4 & 3.4 & 7 & 5.4 & 18 & 4.2 \\
\hline Laparoscopy & 4 & 9 & 21 & 15.8 & 17 & 14.5 & 21 & 16.2 & 63 & 14.8 \\
\hline Other test/procedure $\ddagger$ & 32 & 70 & 81 & 60.9 & 81 & 69.2 & 77 & 59.2 & 271 & 63.6 \\
\hline Total & 145 & & 433 & & 405 & & 468 & & 1451 & \\
\hline \multicolumn{11}{|l|}{ Chemotherapy§ } \\
\hline Fluorouracil & 924 & 43 & 2930 & 45.9 & 1898 & 43.6 & 3019 & 40.0 & 8771 & 79.1 \\
\hline Cisplatin & 100 & 37 & 411 & 33.1 & 349 & 36.8 & 333 & 27.7 & 1193 & 60.1 \\
\hline Epirubicin hydrochloride & 32 & 5 & 53 & 3.0 & 38 & 4.3 & 147 & 7.7 & 270 & 10.1 \\
\hline Carboplatin & 112 & 1 & 126 & 0.8 & 84 & 0.0 & 470 & 2.3 & 792 & 2.1 \\
\hline Other & 71 & 11 & 201 & 14.3 & 238 & 12.8 & 416 & 19.2 & 926 & 33.1 \\
\hline Total & 1239 & 72 & 3721 & 82.7 & 2607 & 84.6 & 4385 & 82.3 & 11952 & 81.9 \\
\hline Radiotherapy & 214 & 80 & 679 & 85.0 & 564 & 82.9 & 481 & 76.9 & 1938 & 80.9 \\
\hline Initial investigations after adjuvant therapy & 213 & 85 & 617 & 91.7 & 565 & 88.9 & 391 & 82.3 & 1782 & 87.1 \\
\hline Subsquent investigations & 48 & 24 & 117 & 23.3 & 111 & 29.1 & 188 & 30.8 & 464 & 27.0 \\
\hline \multicolumn{11}{|l|}{ Endoscopic therapy } \\
\hline Argon plasma coagulation & 0 & 0 & 4 & 3.0 & 2 & 1.7 & 3 & 2.3 & 9 & 2.1 \\
\hline Photodynamic therapy & 1 & 2 & 0 & 0 & 2 & 1.7 & 0 & 0 & 3 & 0.7 \\
\hline Endoscopic stent placement & 12 & 26 & 30 & 22.6 & 41 & 35.0 & 30 & 23.1 & $125 \#$ & 29.3 \\
\hline
\end{tabular}




$\begin{array}{lcccccccccc}\text { Endoscopic laser therapy } & 1 & 2 & 3 & 2.3 & 5 & 4.3 & 6 & 4.6 & 15 & 3.3 \\ \text { Total } & 14 & 30 & 37 & 27.8 & 50 & 42.7 & 39 & 30.0 & 140 & 32.9\end{array}$

*Cancer stage was imputed using regression methods for half the sample where data were missing. †Endoscopy was a condition of entry into the study. ¥Includes additional positron emission tomography (PET) or computed tomography (CT) in the diagnostic phase. $\S$ Values denote the number of administrations for the four most commonly employed agents; some patients received more than one agent. TValues denote number of weeks of radiotherapy. \#Some patients had more than one stent placement. 
Table 3 Frequency of adverse events after oesophagectomy ( $n=665)$

\begin{tabular}{lcc}
\hline & $n$ & \% patients \\
\hline Pneumonia & 121 & 18.2 \\
Arrhythmia & 72 & 10.8 \\
Anastomotic leak & 67 & 10.1 \\
Wound infection & 55 & 8.3 \\
Respiratory failure & 29 & 4.4 \\
Chyle leak & 27 & 4.1 \\
Septic shock & 23 & 3.5 \\
DVT/PE & 22 & 3.3 \\
Bleeding & 16 & 2.4 \\
Renal failure & 7 & 1.1 \\
Postop. multiorgan failure & 2 & 0.3 \\
Other & 163 & 24.5 \\
\hline
\end{tabular}

*No. of patients with at least one adverse event. Seven surgical patients had missing data for adverse events. DVT/PE, deep vein thrombosis/pulmonary embolism. 
Table 4 Unadjusted costs by resource categories by non-surgical and surgical cases*

\begin{tabular}{|c|c|c|c|c|}
\hline & \multicolumn{2}{|c|}{ Non-surgical patients $(n=426)$} & \multicolumn{2}{|c|}{ Surgical patients ( $n=672)$} \\
\hline & No. affected & Cost $(€) \dagger$ & No. affected & Cost $(€) \dagger$ \\
\hline Peridiagnostic investigations & 426 & $507153(6.9)$ & 672 & 825800 (3.3) \\
\hline Endoscopic therapy (any) & 141 & $350341(4.8)$ & 62 & $125918(0.5)$ \\
\hline \multicolumn{5}{|l|}{ Chemotherapy } \\
\hline Drugs (all) & 350 & $298581(4.1)$ & 370 & $384951(1.5)$ \\
\hline Clinical cost/admin & 350 & $4198184(57.0)$ & 370 & 4804299 (19.2) \\
\hline Radiotherapy & 347 & 1164709 (15.8) & 295 & $884982(3.5)$ \\
\hline Investigations (initial) & 371 & $593345(8.1)$ & 213 & $168400(0.7)$ \\
\hline Surgery & 0 & $0(0)$ & 672 & $16596620(66.4)$ \\
\hline Postop. investigations & 0 & $0(0)$ & 553 & $755339(3.0)$ \\
\hline Investigations (subsequent) & 116 & $156618(2.1)$ & 185 & $225754(0.9)$ \\
\hline Doctor consultations & 426 & $92956(1.3)$ & 672 & $222532(0.9)$ \\
\hline Total cost $(€)$ & & $7361887(100)$ & & $24994595(100)$ \\
\hline Mean(s.d.) & & 17 281(16 299) & & 37 195(22 763) \\
\hline Median & & 13066 & & 29114 \\
\hline 95th percentile & & 49850 & & 83324 \\
\hline
\end{tabular}

Values in parentheses are percentages of the total cost. *Two patients with no data on surgical intervention were excluded. †Currency conversion used was 2009 Australian dollars (AUD): 1 AUD $=€ 0.519$ (Organisation for Economic Co-operation and Development purchasing power parity). 